Research Article

\title{
An Experimental Apparatus for Monitoring Radon during Compression of Coal/Rock Samples and Its Preliminary Application
}

\author{
Wei Zhang, ${ }^{1,2}$ Kaidi Xie, ${ }^{2}$ Yanchao Zhu ${ }^{D},{ }^{2}$ Yandong Zhang, ${ }^{2}$ Xu Duan, ${ }^{2}$ and Jibo Zhu ${ }^{2}$ \\ ${ }^{1}$ State Key Laboratory of Coal Resources and Safe Mining, China University of Mining and Technology, Xuzhou 221116, China \\ ${ }^{2}$ School of Mines, China University of Mining and Technology, Xuzhou 221116, China \\ Correspondence should be addressed to Yanchao Zhu; yanchaozhu@cumt.edu.cn
}

Received 10 December 2020; Revised 17 December 2020; Accepted 6 January 2021; Published 18 January 2021

Academic Editor: Hualei Zhang

Copyright (c) 2021 Wei Zhang et al. This is an open access article distributed under the Creative Commons Attribution License, which permits unrestricted use, distribution, and reproduction in any medium, provided the original work is properly cited.

Based on the radionuclide distributions in sedimentary coal-bearing strata, this study analyzed the microrelease mechanisms of radon in coal-bearing strata. It was found that the microrelease process includes three stages: emanation, migration, and exhalation. Based on this, an experimental apparatus was independently designed for monitoring radon during compression of coal/ rock samples from coal-bearing strata, whose major components include an electrohydraulic servocontrolled rock mechanics testing system, an airtight container, coal/rock samples, radon output device, and a continuous emanometer. The developed apparatus was preliminarily utilized for uniaxial compression tests on mudstone samples taken from the \#21105 coalface of the Fourth Coal Mine in Yili Coalfield, China. The test results show that before sample failure under the uniaxial compressive load (UCL), the radon concentration is negatively correlated with the applied UCL and the magnitude of imposed elastic deformation. Increasing the applied load shortens the period of stable deformation, gradually decreasing the porosity of the rock, and as a result of declining the concentration of radon emanation from the rock. Finally, suggestions for future research are proposed, including mathematical equations to express the correlations between different experimental parameters and fractal characteristics of radon release from porous media.

\section{Introduction}

Radon (Rn) was first discovered from minerals containing radium in 1990. Since then, this radioactive element and its decay products have received growing attention. A great deal of research has been conducted to investigate the movement mechanisms of radon from deep underground to the ground surface, e.g., diffusion and convection action [1], pore fluid action [2], transportation by microbubbles [3], relay transmission [4], stress squeezing [5], deep-penetrating geochemistry [6], composite cluster theory [7], and radon's inherent tendency to move upward [8]. Despite different explanations, it is an indisputable fact that radon can migrate from underground to the surface.

In the decay series of uranium, uranium decays to radium and then radium decays to radon. Uranium is widely found in the natural environment, including the atmosphere, surface soil, subsurface coal-bearing strata, and groundwater, leading to its ubiquity in the natural world $[9,10]$. The continuous development of modern science and technology has enabled scientists to use radon as a tracer to solve various engineering problems, e.g., exploration of subsurface mineral deposits [11], prediction of geological hazards [12], detection of concealed goaves in coal mines [13].

Mining-induced coal-rock failure is the major cause of serious accidents during underground coal mining. Therefore, understanding the failure mechanism of coal-rock mass and obtaining critical information about the failure has become an important direction of research in the field of rock mechanics. Conventional methods include microseismic monitoring [14], acoustic emission [15], electromagnetic radiation [16], infrared radiation [17], transient electromagnetics [18], electrical prospecting [19], and 
ultrasound detection [20]. In recent years, radiation measurement based on radon's properties has been utilized in underground coal mining in China [21]. This led to initial attempts to detect radon released by mining-induced overburden deformation and failure, with an aim to develop an innovative radon detection method for advanced forecasting of accidents [22-24]. To ensure the reliability and accuracy of the current radon detection method in solving engineering problems related to coal mines, some fundamental issues need to be further studied, such as the relationship between radon concentration and coal/rock deformation.

For this reason, this study analyzed the microrelease mechanisms of radon in coal-bearing strata. On this basis, an experimental apparatus for monitoring radon during compression of coal/rock samples was independently developed. Then, the experimental apparatus was preliminarily utilized to conduct uniaxial compression tests on rock samples (mudstone). Furthermore, suggestions for future research are provided in this paper related to mathematical equations to show the correlations between the experimental parameters and fractal characteristics of radon release from porous media.

\section{Microrelease Mechanism of Radon}

Coal-bearing strata, a lithostratigraphic term, refer to a succession of sedimentary strata containing coal streaks or seams from a certain period of time in geological history, in which coal is often accompanied by other minerals [25]. The content of radionuclides in an underground coal seam depends on the elementary composition of the source material from which the coal has been produced and the geophysical and geochemical processes it has undergone during and after coal formation. Zhu et al. have found that the absorption of radioactive substances by humic acids and humus, two organic compounds of coal, during the initial stage of coal formation, is a key contributor to the enrichment of radioactive elements in coal [26]. Uranium has a great affinity for organic matters and is widely found in lowgrade metamorphic coals, especially brown coals. Commercially recoverable coal seams that are rich in uranium were mostly deposited in continental environments. As we know, the uranium-absorbing capacity of coal gradually decreases with greater intensity of metamorphism, while the diffusion and convection can promote the transference and accumulation of the uranium released from a coal seam to the roof strata. As the gangue surrounding coal seams in continental facies is mostly composed of mudstone, it is likely to have a high level of radioactivity. Additionally, the radionuclides present in the overlying soil are normally sourced from bedrock, which has a bearing on the composition and structure of coal-bearing strata [27]. Therefore, the continental depositional environment provides a sound geological basis for radon release.

Coal seams, broken rocks, and mine water are the major sources of radon in underground coal mines [28]. Radon atoms originated in the decay of radium within the solid components of the strata may not be released into the pore space due to their very low diffusion coefficients. However, when radon atoms escape into the space between the particles, they may be released to the surface atmosphere [29]. Figure 1 illustrates the whole microrelease process of radon atoms from underground strata to the surface atmosphere. Strata or soil represent the $\mathrm{U}$ - and Ra-bearing materials that can release radon, which consists of fine particles with different shapes, sizes, and pores at a microscale. The microrelease process of radon includes the following three stages: (a) Emanation, the process by which radon atoms move from the grains of source material to the intergranular space; (b) Migration, the process of diffusion and convection that causes the movement of the emanated radon atoms through the material to the ground surface; (c) Exhalation, the process by which radon atoms move from the ground surface into the surface atmosphere.

\section{Experimental Apparatus Design}

The experimental apparatus for monitoring radon during compression of coal/rock samples mainly consists of an electrohydraulic servocontrolled rock mechanics testing system (MTS815, MTS Systems Corporation, Eden Prairie, Minnesota, America), an airtight container, coal/rock samples, radon output device, and a continuous emanometer (KJD-2000R, Xstar Company, Sichuan, China), as shown in Figure 2. The experimental apparatus is easy to assemble, disassemble, and operate, while the required raw materials are easily machinable. Moreover, it allows direct observation of the coal/rock sample's morphological change during the test process. In particular, the background concentration of radon can be elevated by adjusting the radon output device to reduce test errors.

3.1. Design of the Airtight Container. The airtight container is made of $1 \mathrm{~cm}$ thick toughened glass. It is cylindrical in shape, with a height of $30 \mathrm{~cm}$ and a diameter of $25 \mathrm{~cm}$, and consists of a bottom, a wall, and a removable cover, as shown in Figure 3. There is a pair of symmetric lifting eyes on the removable cover for manually lifting the removable cover. The airtight container wall has an air inlet and an air outlet in its lower-middle part, which are connected to the radon output device and the continuous emanometer, respectively. A rubber gasket is attached to the edge of the removable cover in order to prevent leakage between the cover and the wall. Moreover, to prevent the removable cover from sliding down during testing, the rubber gasket is required to offer a frictional force that can balance the force of gravity acting on the removable cover.

3.2. Design of the Radon Output Device. The radon output device consists of a pedestal and a steel shell mounted on it, as shown in Figure 4 . It is filled with about $1 \mathrm{~kg}$ of tailings from a uraninite residue, used as the radon source. The shell is lead-coated to shield the experimenters against the radioactive material radiation. One end of the shell is connected to a gas pipe with an adjustable valve to control the radon flow into the airtight container and thereby regulating 


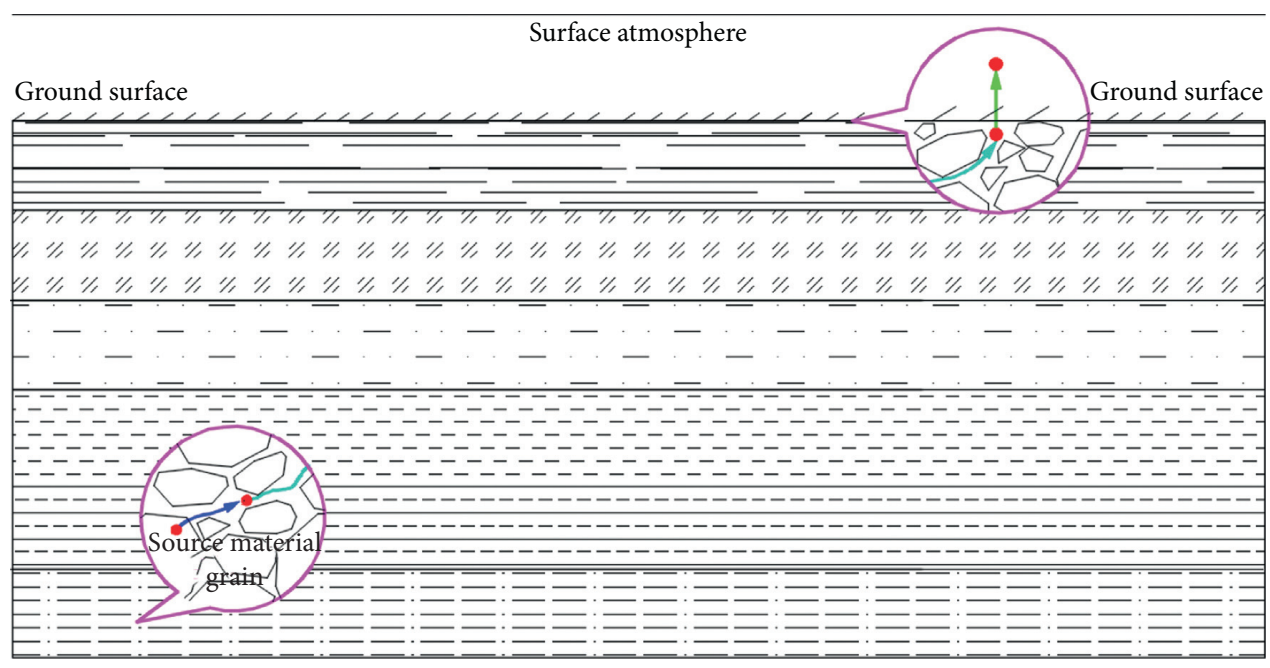

Radon atom

Emanation

— Migration

_Exhalation

Figure 1: The microrelease process of radon atoms.

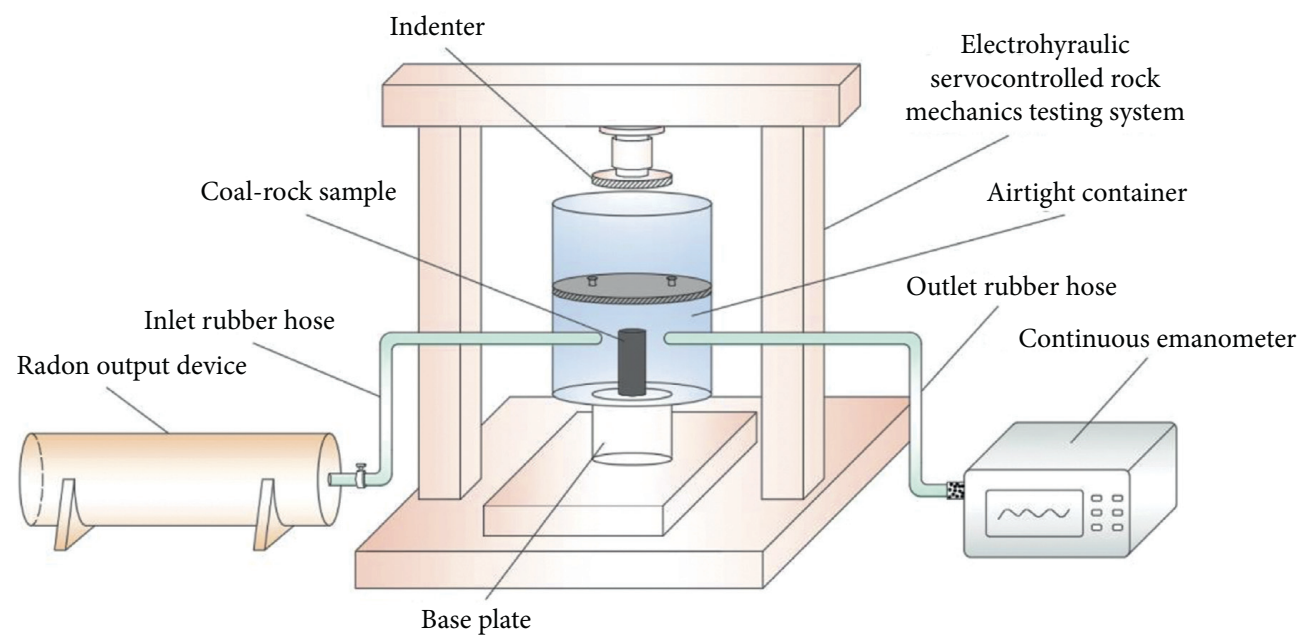

Figure 2: Schematic of the experimental apparatus.

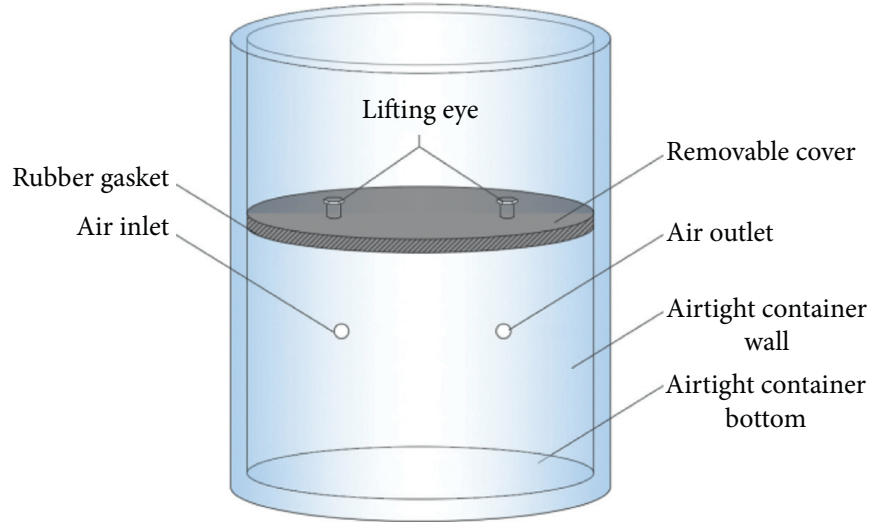

(a)

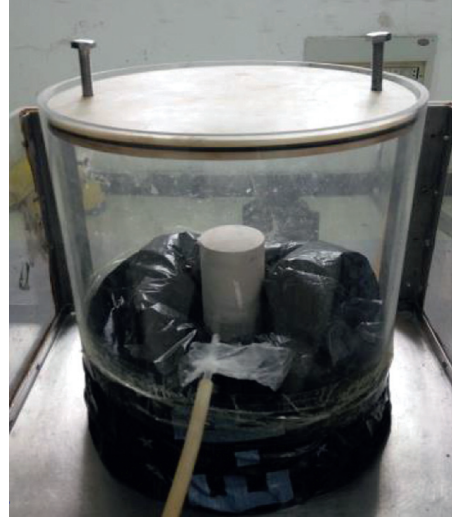

(b)

Figure 3: Schematic of the airtight container: (a) structure shape and (b) physical photograph. 


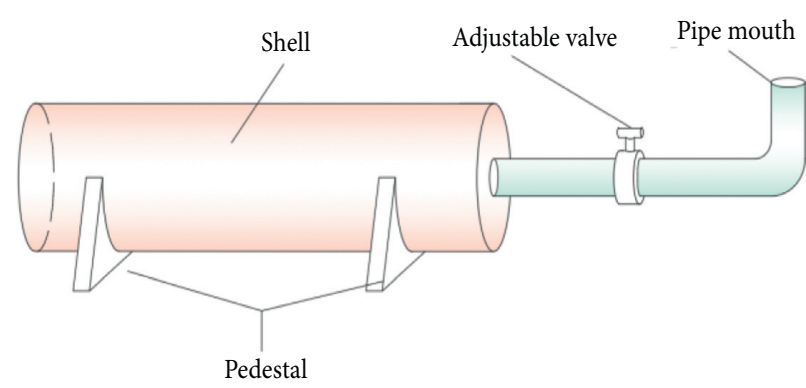

(a)

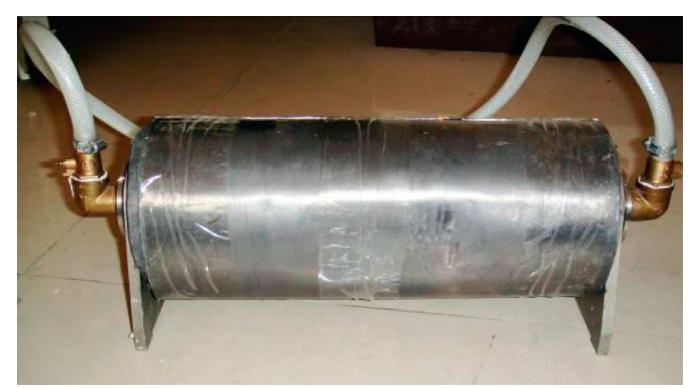

(b)

FIGURE 4: Schematic of the radon output device: (a) structure shape and (b) physical photograph.

the background concentration of radon. The pipe mouth is connected to the air inlet of the airtight container via the inlet rubber hose.

3.3. Selection of the Continuous Emanometer. The traditional types of instantaneous emanometers, e.g., FD-3017 emanometer, can be used to accurately measure radon concentrations, but they are incapable of providing continuous measurements. Therefore, KJD-2000R emanometer, a continuous emanometer, was selected as the measuring instrument, as shown in Figure 5. KJD-2000R continuous emanometer has multiple advantages, including being portable, flexible, highly sensitive, and is able to provide continuous measurements over a wide concentration range. The KJD-2000R emanometer is linked by an outlet rubber hose to the air outlet in the airtight container wall.

3.4. Specific Implementation Method. The utilized MTS815 test system has a base plate at its bottom and an indenter at its top, with the airtight container placed in between. The following steps were undertaken for conducting the tests: (a) Each coal/rock sample was appropriately put into the airtight container as required; (b) The valve was opened to let the radon output device input radon into the airtight container; (c) The MTS815 test system applied a uniaxial compressive load to the coal/rock sample and the KJD2000R continuous emanometer measured the radon concentrations during compression of the sample. To enhance the airtightness of the whole experimental apparatus, the pipe mouth, air inlet, and outlet and the connection between the continuous emanometer and the outlet rubber hose were sealed with butter. After the completion of tests, the obtained data were processed to analyze the pattern of variation in radon concentration during compression of the coal/rock samples.

\section{Preliminary Application}

The experimental apparatus described above was preliminarily utilized for uniaxial compressive tests on rock samples to test its reliability. The measurements from the experimental apparatus were then analyzed to investigate the pattern of variation in radon concentration during the compression of the samples. The tests were conducted at the State Key
Laboratory of Coal Resources and Safe Mining, China University of Mining and Technology, Xuzhou City, Jiangsu Province, China. For safety reasons, we have measured the radon concentration of the five places in the experimental hall (as shown in Figure 6). The results show that the average value of radon concentration is $8.5 \mathrm{~Bq} / \mathrm{m}^{3}$, which is satisfied with the limiting value $\left(400 \mathrm{~Bq} / \mathrm{m}^{3}\right)$ of second-class civil construction engineering in "State Standard of the People's Republic of China: Code for Indoor Environmental Pollution Control of Civil Building Engineering (GB50325-2010).” Therefore, the experimental environment is safe enough for technicians [30].

4.1. Rock Samples Preparation and Test Procedure. The utilized mudstone samples were obtained through a combination of ground drilling and underground sampling from the \#21105 coalface of the Fourth Coal Mine in Yili Coalfield, Xinjiang Autonomous Region, China. The sampled mudstone consisted of quartz, feldspar, and uranium gel, with particle sizes ranging from 0.3 to $0.65 \mathrm{~mm}$. During sampling, cylindrical rock samples (\#1 to \#3) with a diameter of $50 \mathrm{~mm}$ and a height of $100 \mathrm{~mm}$ were obtained by drilling, following the relevant standard (GB/T 23561.7-2009: Methods for determining the physical and mechanical properties of coal and rock-Part 7: Methods for determining the uniaxial compressive strength and counting softening coefficient). Thereafter, the samples were polished so that the difference in the parallelism of the two end surfaces was less than $0.02 \mathrm{~mm}$, the perpendicularity of the two end surfaces to the sample axis was less than 3.5 seconds, and the surface roughness of the samples was less than $0.3 \mathrm{~mm}$. Finally, polished samples were dried for 24 hours, and they were sealed before being used for the uniaxial compression tests. The uniaxial compression tests were conducted using the MTS815 test system with a maximum axial pressure of $4600 \mathrm{kN}$ and a loading rate in the range of 0.1 to $0.5 \mathrm{kN} / \mathrm{s}$. Loading and strains were measured using a dynamic strainmeter. Figure 7 shows examples of the prepared rock samples and the test procedure.

4.2. Analysis of Experiment Results. The results of uniaxial compression tests show that after the uniaxial compressive load exceeded $16.75 \mathrm{MPa}$ (the corresponding maximum 


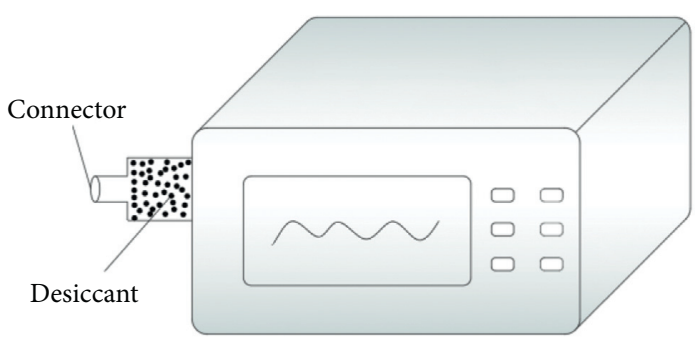

(a)

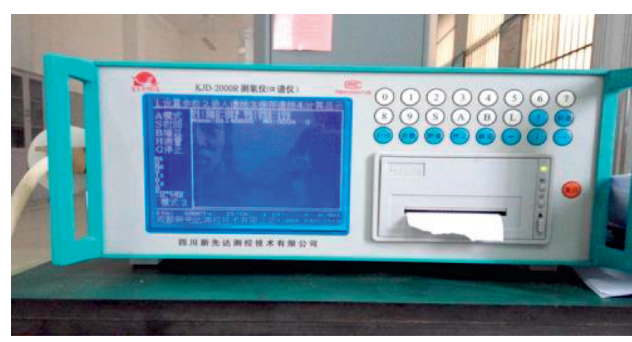

(b)

FIgURE 5: Schematic of the KJD-2000R emanometer: (a) structure shape and (b) physical photograph.

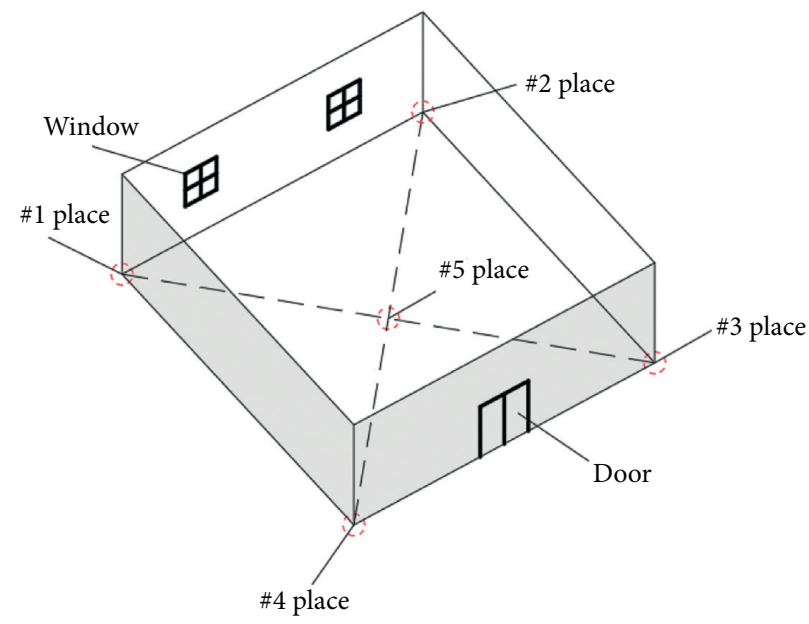

Figure 6: Schematic of five places in the experimental hall.

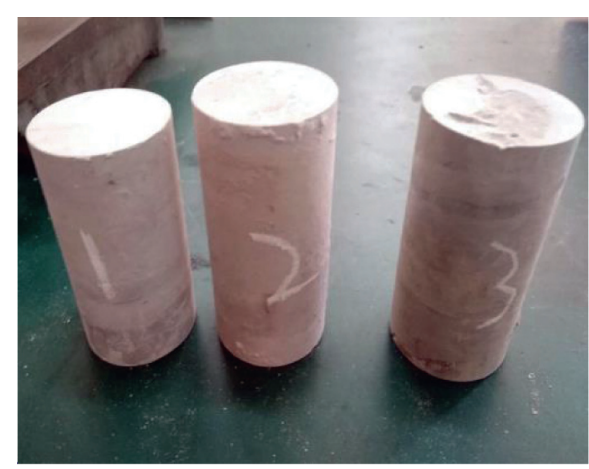

(a)

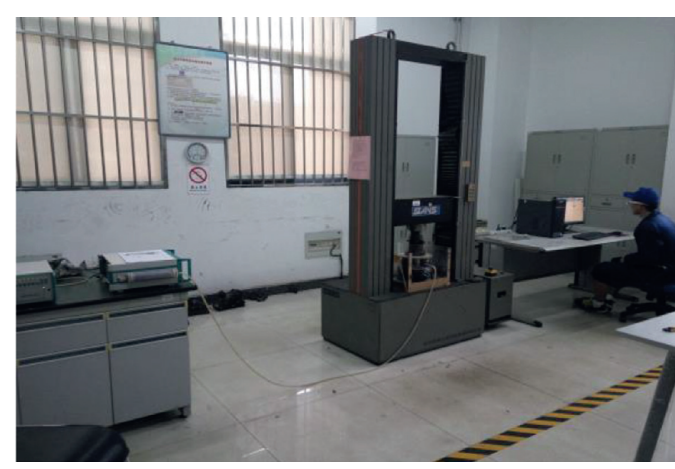

(b)

FIGURE 7: Rock samples preparation and test procedure: (a) mudstone samples and (b) test procedure.

axial deformation was $2.4 \mathrm{~mm}$ ) (as shown in Figure 8, specific data are presented in Tables 1 and 2), cracks formed in mudstone sample and it failed eventually, which indicates that the limit strength of this mudstone sample is about 16.75 MPa. Therefore, the loading strength for the test on samples (\#1-\#3) was set at $5 \mathrm{MPa}, 10 \mathrm{MPa}$, and $15 \mathrm{MPa}$, respectively. The radon concentration in the radon output device delivered to the airtight container was set at $200 \mathrm{~Bq} /$ $\mathrm{m}^{3}$. The decay constant of radon is $2.097 \times 10^{-6} / \mathrm{s}$. It usually takes about 30 days to reach radioactive equilibrium for radium decay becoming radon, as well as the emanometer just measures the ${ }^{222} \mathrm{Rn}$ itself. For this reason, we could take no account of the effect of radon decay, which would not affect the experiment precision. Radon concentration measurement was conducted when a constant strength of $2 \mathrm{MPa}$ was applied for $5 \mathrm{~min}$ on three samples. Table 1 is the measured radon concentration of samples during the experiment. Figure 9 shows the axial deformations and radon concentrations of samples against loading time under different UCL. Uniaxial deformations of samples increased gradually and eventually stabilized before the sample's failure. This process can be divided into three stages, including transient loading strain, attenuated strain, and allostasis. Although there were no microphotographs of rock 


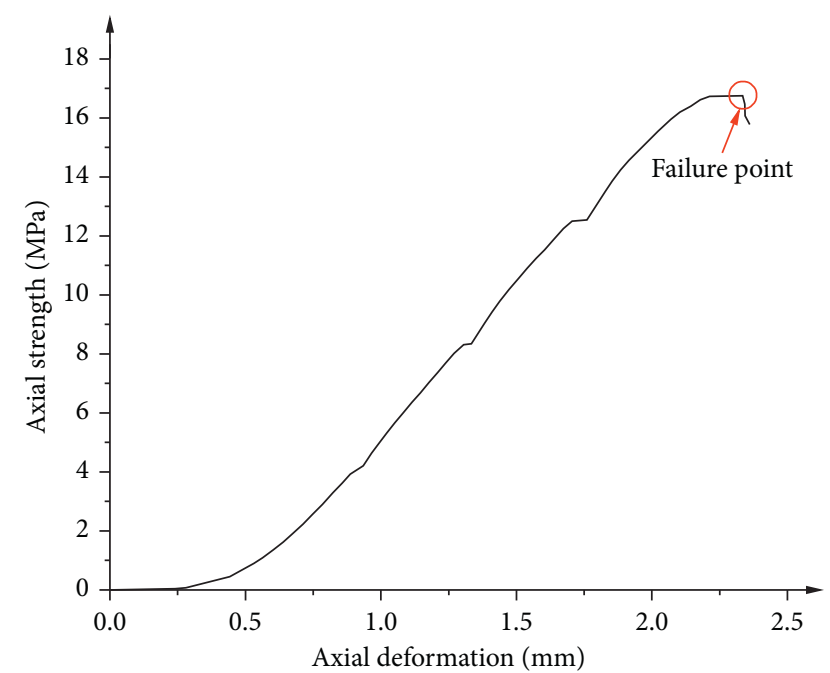

Figure 8: Axial deformation variation with axial strength for mudstone sample.

TABLE 1: The measured radon concentrations of three samples.

\begin{tabular}{lccc}
\hline $\begin{array}{l}\text { Time } \\
(\mathrm{min})\end{array}$ & $\begin{array}{c}\text { \#1 sample } \\
\left(\mathrm{Bq} / \mathrm{m}^{3}\right)\end{array}$ & $\begin{array}{c}\text { \#2 sample } \\
\left(\mathrm{Bq} / \mathrm{m}^{3}\right)\end{array}$ & $\begin{array}{c}\text { \#3 sample } \\
\left(\mathrm{Bq} / \mathrm{m}^{3}\right)\end{array}$ \\
\hline 5 & 477 & 473 & 472 \\
10 & 451 & 421 & 349 \\
15 & 433 & 386 & 297 \\
20 & 417 & 359 & 273 \\
25 & 406 & 337 & 258 \\
30 & 396 & 323 & 248 \\
35 & 384 & 312 & 244 \\
40 & 374 & 304 & 240 \\
45 & 368 & 299 & 237 \\
50 & 360 & 296 & 238 \\
55 & 356 & 297 & 239 \\
60 & 353 & 296 & 239 \\
65 & 352 & 298 & 238 \\
70 & 352 & 296 & 242 \\
75 & 349 & 299 & 240 \\
80 & 350 & 299 & 242 \\
85 & 348 & 302 & 242 \\
90 & 347 & 300 & 242 \\
95 & 347 & 302 & 244 \\
100 & 349 & 304 & 244 \\
105 & 348 & 304 & 245 \\
110 & 349 & 302 & 245 \\
115 & 348 & 302 & 246 \\
120 & 349 & 302 & 249 \\
\hline & & &
\end{tabular}

microstructures, acoustic emissions, or porosity data, based on the variation features of radon concentrations, an inference can be made as follows: Initially, uniaxial deformations and strain rates of the samples were relatively high, indicating compression of the internal open structures and microcracks. The rate of axial deformation decreased with the increase in the loading time. The results also reveal that uniaxial deformations were positively related to UCL and the loading time for deformation to reach a stable state. These also reveal that the internal porosity of samples decreased as the UCL was increased [31].
TABLE 2: The axial deformation of three samples.

\begin{tabular}{lccc}
\hline Time $(\mathrm{min})$ & \#1 sample $(\mathrm{mm})$ & \#2 sample $(\mathrm{mm})$ & \#3 sample $(\mathrm{mm})$ \\
\hline 0 & 0.280 & 0.153 & 0.056 \\
5 & 0.428 & 0.186 & 0.063 \\
10 & 0.680 & 0.247 & 0.084 \\
15 & 1.014 & 0.330 & 0.116 \\
20 & 1.225 & 0.460 & 0.155 \\
25 & 1.360 & 0.600 & 0.227 \\
30 & 1.464 & 0.708 & 0.287 \\
35 & 1.587 & 0.800 & 0.339 \\
40 & 1.696 & 0.887 & 0.400 \\
45 & 1.884 & 0.928 & 0.447 \\
50 & 2.094 & 1.010 & 0.489 \\
55 & 2.290 & 1.080 & 0.521 \\
60 & 2.348 & 1.148 & 0.563 \\
65 & 2.377 & 1.265 & 0.616 \\
70 & 2.384 & 1.440 & 0.689 \\
75 & 2.391 & 1.560 & 0.774 \\
80 & 2.400 & 1.574 & 0.879 \\
85 & 2.400 & 1.567 & 0.984 \\
90 & 2.406 & 1.581 & 1.021 \\
95 & 2.406 & 1.588 & 1.021 \\
100 & 2.409 & 1.588 & 1.026 \\
105 & 2.406 & 1.588 & 1.026 \\
110 & 2.406 & 1.588 & 1.037 \\
115 & 2.413 & 1.595 & 1.032 \\
120 & 2.413 & 1.600 & 1.032 \\
\hline
\end{tabular}

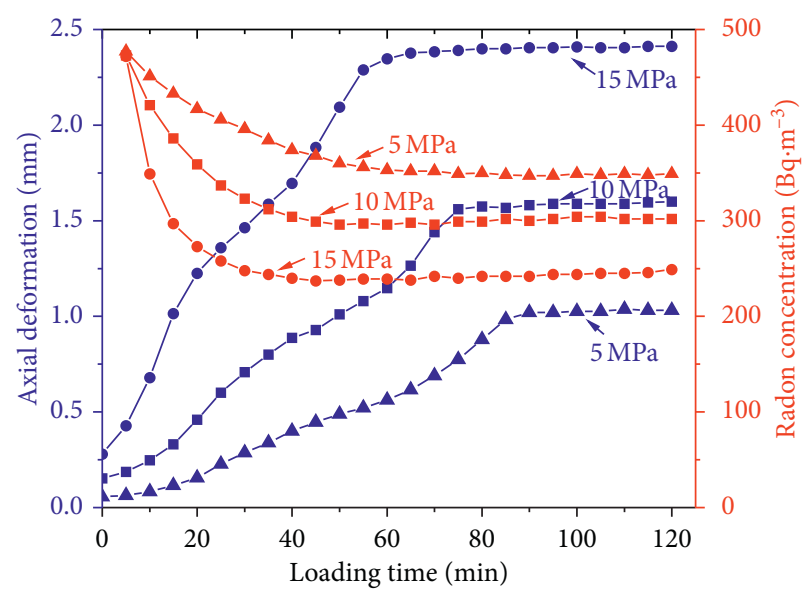

Figure 9: The gradient of different UCL.

\section{Suggestions}

Over the past century, new methods for measuring radiation have been developed and new applications have been discovered. It should be pointed out that various engineering applications of radiation measurements are still in the initial stages of development. In particular, the serious lack of fundamental knowledge poses an obstacle to the improvements in such technologies. The experimental results reported in this paper are based on limited rock samples with a specific condition. Thereby, more studies are needed to address the corresponding issues. For example, on the one hand, from the perspective of refinement, explore the correlations between different experimental parameters, 
especially how to use the mathematical equations to express the above correlations, which will be an important aspect of future research. On the other hand, the release of radon from coal/rock is a complex process that is affected by multiple external and internal factors [32], such as lithology, the content of radium isotopes, pore size, porosity, particle size, permeability, emanation coefficient, air pressure, temperature, humidity, and wind speed. In addition, considering the complex interior structures of porous media, future research can use the fractal theory to study the radon release from porous media and to apply it in the management of the radioactive environment. A recommended approach to radon prevention and mitigation is to reduce the radon release rate by changing the fractal structure of porous media.

\section{Conclusion}

In this study, the microrelease mechanisms of radon in coalbearing strata were analyzed, an experimental apparatus was independently designed for monitoring radon during compression of coal/rock samples from coal-bearing strata, and the apparatus was preliminarily utilized for uniaxial compression tests on mudstone samples taken from \#21105 coalface of the Fourth Coal Mine in Yili Coalfield, China. The following conclusions were obtained:

(1) All coal-bearing strata are more or less radioactive. The continental depositional environment of coal provides a sound geological basis for the radon radon release. The microrelease process of radon atoms includes the following three stages: (a) Emanation, the process of radon atoms moving from the particles of source material to the intergranular space; (b) Migration, the process of diffusion and convection driving the movement of the emanated radon atoms through the material to the ground surface; (c) Exhalation, the process of radon atoms moving from the ground surface into the surface atmosphere.

(2) The experimental apparatus during compression of coal/rock samples mainly includes a MTS815 test system, an airtight container, coal-rock samples, a radon output device, and a KJD-2000R continuous emanometer. This apparatus is easy to assemble, disassemble, and operate, while the required raw materials are easily machinable. Moreover, it allows direct observation of the tested sample's morphological change during testing. In particular, the background concentration of radon can be elevated by adjusting the radon output device to reduce test errors.

(3) The test results indicate that before the failure of rock samples, the elastic deformations and radon concentrations were correlated with the UCL, i.e., positively and negatively, respectively. Furthermore, the time needed for deformations to reach the stable state and internal porosity of samples decreased as the UCL was increased, resulting in reduced radon concentrations. The above results also further verified the reliability of the experimental apparatus for monitoring radon.

\section{Data Availability}

The article data used to support the findings of this study are available from the corresponding author upon request.

\section{Conflicts of Interest}

The authors declare that there are no conflicts of interest regarding the publication of this paper.

\section{Acknowledgments}

This work was financially supported by the National Natural Science Foundation of China (Nos. 51874278 and 51974291), the Foundation Research Project of Jiangsu Province (No. BK20181357), the "Six Talent Peaks" Project of Jiangsu Province (No. JNHB-087), the Talent Support Project of Jiangsu Association for Science and Technology (No. 2019134), and the Independent Research Project of State Key Laboratory of Coal Resources and Safe Mining (No. SKLCRSM2020X04). The authors wish to thank the Fourth Coal Mine in Yili Coalfield, China, for supporting field help to conduct this important study. Special thanks are due to Mapletrans Company in Wuhan, China, for its professional English editing service.

\section{References}

[1] R. L. Fleischer and A. Mogro-Campero, "Radon enhancements in the earth: evidence for intermittent upflows?" Geophysical Research Letters, vol. 6, no. 5, pp. 361-364, 1979.

[2] N. M. Soonawala and W. M. Telford, "Movement of radon in overburden," Geophysics, vol. 45, no. 8, pp. 1297-1315, 1980.

[3] A. Vàrhegyi, J. Hakl, M. Monnin, J. P. Morin, and J. L. Seidel, "Experimental study of radon transport in water as test for a transportation microbubble model," Journal of Applied Geophysics, vol. 29, no. 1, pp. 37-46, 1992.

[4] H. S. Wu, Y. S. Bai, Y. F. Lin, and G. L. Chang, "The action of relay transmission of the radon migration," Chinese Journal of Geophysics, vol. 40, no. 1, pp. 136-142, 1997.

[5] K. Wattananikorn, M. Kanaree, and S. Wiboolsake, "Soil gas radon as an earthquake precursor: some considerations on data improvement," Radiation Measurements, vol. 29, no. 6, pp. 593-598, 1998.

[6] X. J. Xie, "Tactical and strategic deep-penetration geochemical surveys," Earth Science Frontiers, vol. 5, no. 1/2, pp. 171-183, 1998.

[7] W. Y. Jia, F. Fang, R. S. Zhou et al., "Internal causes of radon and its daughters upward migration and cluster phenomenon," Journal of Chengdu University of Technology, vol. 26, no. 4, pp. 171-175, 1999.

[8] H. F. Liu, W. Y. Jia, G. Z. Wang, H. J. Duan, and F. Fang, "The experimental studies of Rn and its daughters' migration law," Journal of Taiyuan University of Technology, vol. 29, no. 2, pp. 109-114, 1998.

[9] M. Antonopoulos-domis, S. Xanthos, A. Clouvas, and D. Alifrangis, "Experimental and theoretical study of radon 
distribution in soil," Health Physics, vol. 97, no. 4, pp. 322-331, 2009.

[10] P. Nandakumaran, N. Vinayachandran, T. S. Anitha Shyam, B. Jose, M. S. Sreehari Sarangan, and M. Santhana Subramani, "Radon in groundwater in parts of coastal tracts of southern Kerala, India," Journal of Radioanalytical and Nuclear Chemistry, vol. 308, no. 1, pp. 99-104, 2016.

[11] Z. X. Shen, "The application of radon survey by activated carbon in the exploration of sandstone-type uranium deposit in Teguidda, Niger," Uranium Geology, vol. 28, no. 4, pp. 250-256, 2012.

[12] V. M. Choubey, S. K. Bartarya, and R. C. Ramola, "Radon variations in an active landslide zone along the Pindar river, in Chamoli district, Garhwal lesser Himalaya, India," Environmental Geology, vol. 47, no. 6, pp. 745-750, 2005.

[13] J. H. Liu, Z. W. Wang, S. Zhu, A. H. Weng, and A. Y. Xia, “The geophysical exploration about exhausted area and sinking area in coalmine," Journal of China Coal Society, vol. 30, no. 6, pp. 715-719, 2005.

[14] D. Amitrano, M. Arattano, M. Chiarle et al., "Microseismic activity analysis for the study of the rupture mechanisms in unstable rock masses," Natural Hazards and Earth System Sciences, vol. 10, no. 4, pp. 831-841, 2010.

[15] M. C. He, J. L. Miao, and J. L. Feng, "Rock burst process of limestone and its acoustic emission characteristics under truetriaxial unloading conditions," International Journal of Rock Mechanics and Mining Sciences, vol. 47, no. 2, pp. 286-298, 2010.

[16] V. Frid and K. Vozoff, "Electromagnetic radiation induced by mining rock failure," International Journal of Coal Geology, vol. 64, no. 1-2, pp. 57-65, 2005.

[17] H. Sun, L. Q. Ma, N. Adeleke, and Y. Zhang, "Background thermal noise correction methodology for average infrared radiation temperature of coal under uniaxial loading," Infrared Physics \& Technology, vol. 81, no. 1, pp. 157-165, 2017.

[18] D. Triantis, C. Anastasiadis, and I. Stavrakas, "The correlation of electrical charge with strain on stressed rock samples," Natural Hazards and Earth System Sciences, vol. 8, no. 6, pp. 1243-1248, 2008.

[19] L. Y. Huang, S. D. Liu, B. Wang, and F. B. Zhou, "Quantitative calculation of aquifer water quantity using TEM data," Earth Sciences Research Journal, vol. 21, no. 1, pp. 51-56, 2017.

[20] S. Chaki, M. Takarli, and W. P. Agbodjan, "Influence of thermal damage on physical properties of a granite rock: porosity, permeability and ultrasonic wave evolutions," Construction and Building Materials, vol. 22, no. 7, pp. 1456-1461, 2008.

[21] D. S. Zhang, W. Zhang, L. Q. Ma, X. F. Wang, and G. W. Fan, "Developments and prospects of detecting mining-induced fractures in overlying strata by radon," Journal of China University of Mining \& Technology, vol. 45, no. 6, pp. 10821097, 2016.

[22] W. Zhang, D. S. Zhang, D. H. Qi, W. M. Hu, and W. S. Zhang, "Floor failure depth of upper coal seam during close coal seams mining and its novel detection method," Energy Exploration \& Exploitation, vol. 36, no. 5, pp. 1265-1278, 2018.

[23] W. Zhang, Y. Y. Sun, D. S. Zhang et al., "Three-dimensional physical simulation test for activity laws of mining-induced overburden by radon detection in Yili mining area of Xinjiang," Journal of Mining and Safety Engineering, vol. 36, no. 6, pp. 1102-1108, 2019.

[24] W. Zhang, D. S. Zhang, W. M. Hu, Z. Yang, and P. Li, "Preliminary study on radon detection application under condition of mid-deep coal seam mining," Journal of Mining and Safety Engineering, vol. 34, no. 5, pp. 1008-1014, 2017.

[25] K. Skubacz, J. Lebecka, S. Chalupnik, and M. Wysocka, "Possible changes in radiation background of the natural environment caused by coal mine activity," Energy Sources, vol. 14, no. 2, pp. 149-153, 1992.

[26] H. X. Zhu, H. Y. Chen, and W. Zhang, "Metal mineral types and distribution characteristics in coal in Northern China," Journal of China Coal Society, vol. 41, no. 2, pp. 303-309, 2016.

[27] S. Flexser, H. A. Wollenberg, and A. R. Smith, "Distribution of radon sources and effects on radon emanation in granitic soil at Ben Lomond, California," Environmental Geology, vol. 22, no. 2, pp. 162-177, 1993.

[28] T. M. Semkow, "Recoil-emanation theory applied to radon release from mineral grains," Geochimica et Cosmochimica Acta, vol. 54, no. 2, pp. 425-440, 1990.

[29] A. Sakoda, Y. Ishimori, and K. Yamaoka, "A comprehensive review of radon emanation measurements for mineral, rock, soil, mill tailing and fly ash," Applied Radiation and Isotopes, vol. 69, no. 10, pp. 1422-1435, 2011.

[30] J. N. Corrêa, A. C. M. Silva, S. A. Paschuk et al., "Thickness of radon emitting layer in building materials," Radiation Physics and Chemistry, vol. 172, Article ID 108786, 2020.

[31] K. Karaman and A. Kesimal, "Correlation of Schmidt rebound Hardness with uniaxial compressive strength and P-wave velocity of rock materials," Arabian Journal for Science and Engineering, vol. 40, no. 7, pp. 1897-1906, 2015.

[32] P. Sahu, D. C. Panigrahi, and D. P. Mishra, "A comprehensive review on sources of radon and factors affecting radon concentration in underground uranium mines," Environmental Earth Sciences, vol. 75, no. 7, pp. 1-19, 2016. 